\title{
The Medical Contribution to the Management of Mental Mllness Services
}

\author{
D. H. Dick, Director, NHS Health Advisory Service
}

Health Advisory Service visits to services for the mentally ill in recent months keep throwing up a persistent theme: the apparent failure of the medical staff to provide the impetus that is necessary to develop and manage an effective comprehensive psychiatric service based upon the needs of patients rather than on professional or sectional interests.

The observation is framed by visiting teams as 'You know what is wrong in that hospital? There is no medical leadership.' The observation is so frequent that the explanation must be that it is the system of management that is wrong and not only the contribution of individuals. To support this view, it is apparent that muddled and ineffective services are just as frequently to be seen in Health Districts that are staffed by consultants of high clinical and academic reputation as in ones where the quality of medical staff may be quite clearly inferior. Some illustrations will be given later.

\section{Comprehensiveness}

The basic ingredient that is missing is the acknowledgement amongst a body of consultants that they might be corporately responsible for providing a comprehensive service. Individually they may run outstanding departments, but the sum of the parts does not necessarily make a satisfactory whole. Unhappily in some instances consultants, finding themselves unable to influence other parts of the service, withdraw into the only work over which they can exert control. This may lead to the pursuit of personal interests and a distortion of services and priorities. The situation is not unique to psychiatry.

There are many exceptions where services are well run and well organized, in which medical staff work in harmony with each other and with other disciplines. However, the attainment of what is so universally desirable depends too much on luck. It only needs one individual exercising a veto, whilst still fulfilling the obligations of his contract, to destroy the carefully built concord of his colleagues.

\section{Service policies}

During a visit the HAS discusses the service with all levels of management, service providers and consumers. A frequent complaint of Area Teams of Officers and District Management Teams is that they are unable to obtain agreement from the body of psychiatrists on policies and priorities. Often this response is contrasted with the response from surgeons and physicians 'who know exactly what they want'. It is not surprising to find that clearly stated unanimous requests receive priority in times of scarce money. What works for the comparatively simple organizational structure of medical and surgical departments does not work for the department of psychiatry which has to reach out into areas shared with other authorities, institutions and social systems. The range of tasks is also much wider.

At another level, on the chronic wards of some mental hospitals, the effect of fragmentation shows up as leaderless custodial care with no element of therapy because the consultant has chosen to spend his scarce time, quite legitimately, on more pressing and attractive out-patient psychiatry. Responsibility for rehabilitation has been seized by no one, neither has it been assigned.

\section{Examples}

Here are some examples of how development appears to have been held up by the shortcomings of the present organizational structure.

\section{Example 1}

One hospital is dominated by a single senior consultant who won his reputation many years ago through a particular style of care and who will not now accept innovation. He rejects occupational therapy, social workers, community care and even possibly the reorganization of the National Health Service as passing fads. The ATO and the DMT seem powerless to respond to the pressures from the community for improved services. Consultant colleagues have developed their own interests and have only a casual interest in the health of the institution.

\section{Example 2}

A small group of consultants work from a psychiatric unit in a district general hospital providing a district service. Contacts with the parent mental hospital have been severed. No one has an interest in the psychiatry of old age, for which there are no beds. Staffing levels do not justify the appointment of another colleague. Calls to provide services for the elderly mentally infirm are met with 'it is not our job and anyway we have no resources to meet the alleged obligation to develop a service'.

\section{Example 3}

The consultant staffing levels in a teaching Health Area are several times the national figures for psychiatric services. Even so, the service in the community has immense gaps with little available for emergency assessment, no aftercare services, hardly any day hospital places and very primitive arrangements for the psychiatry of old age. There seems to be nothing available for the chronically mentally ill. The plans for a comprehensive service are thin indeed, but liaison psychiatry and special departments are very well developed.

Example 4

The consultant body is in such conflict that patient care suffers. There is evidence of this from the CHC, GPs, letters from patients and internal inquiries held by the AHA. The consultants are polarized into two treatment models which in combination would probably provide a comprehensive service but refusal to work together prevents them from sharing their contribution or their hospitals between two sections of the clinical area which they serve.

Example 5

All eleven consultants admit to the same admission ward, 
declining to develop their own units for fear of ending up with inferior premises.

Example 6

All seven consultants in a large county are available for consultation anywhere in the county. Not only is travelling needlessly duplicated but the community psychiatric nurses and social work teams are in despair of ever developing working relationships with consultants.

Add to these examples the lessons of the inquiries and reviews of the last 12 years, especially Whittingham, St Augustine's and Normansfield, and now Rampton. In each, there is criticism of medical leadership and an assumption that individuals have failed to use a perfectly sound system through personal inadequacy. This must be disputed. The system is clearly unsound.

\section{The chain of secountability}

An Area Health Authority is responsible for providing a comprehensive health service within its Area. This is a delegated responsibility of the Secretary of State to whom the Authority is accountable. The responsibility is further delegated by the AHA to a District Management Team who are accountable to them. At this point the chains of delegation and accountability to provide a comprehensive service seem to vanish. The DMT does not actually provide the service and the consultant medical staff who do are accountable by custom and contract only to the individuals that are referred to them. Further, their contracts are held, in the majority, by a Regional Health Authority and not the Area Health Authority. The principle of comprehensiveness has therefore been lost. There is no individual or group of consultants to whom responsibility can be delegated or who can be held accountable. Medical Executive Committees, Cogwheel Divisions or the elements of the District Medical Committee do not have executive functions despite their names: they are only advisory or co-ordinating bodies. Where the system works at present, it does so by good sense, good will and chance.

Are there remedies? Is it possible to restore the link of accountability between the clinical staff who provide the service and the management system that provides the resources? There was such a link formerly, the medical superintendent, but few would wish to return total responsibility to a single individual for life. There would be little enthusiasm to recombine managerial and medical responsibility in one person. The few remaining medical superintendents or medical directors do not fit easily into the reorganized health services as the questions of responsibility and accountability are even more muddled by the parallel systems.

\section{Consultant contracts}

There is clearly a need to clarify consultant contracts on what the consultant provides as his contribution to a full service and to whom he is accountable. In the United Kingdom at present the consultant is only accountable to the patient who is referred to him and has an obligation to uphold the ethics of his profession. He is not asked to be accountable to a community for patients falling within his specialty who have not been referred to him. There are some precedents, where this is so. In general, psychiatrists accept responsibility for patients who are liable to detention under the Mental Health Act who live within their agreed clinical area.

In some European countries (eg, Jugoslavia) a group of doctors contracts with a local community to provide all medical services following a negotiation about payment and resources. In the United States, prepaid group practice and health maintenance organizations (HMOs) are forms of prepaid health care which have been well accepted and are encouraged by federal government.

To resolve the problems of the medical contribution to the management of mental illness services through an improved contract, it would therefore be necessary to introduce a group responsibility to deliver a comprehensive service. As services continually evolve, it would become necessary to revise the contract regularly.

\section{Monitoring}

It is often quite impossible to know whether a department is performing well, as the only indication that it is not may be an increasing volume of complaints or three-year-old figures collected by the DHSS. Few collect adequate current statistics or analyse trends or check quality. Monitoring annual objectives through proper information would allow the redeployment of staff time and resources to meet deficiencies and poor performance. The service would be the outcome of care rather than a concentration on the structure of care.

\section{Medical administration}

In most mental illness services one consultant temporarily takes on administrative duties on behalf of his colleagues, as others make themselves responsible, for example, for rehabilitation, alcoholism, medical education or the psychiatry of old age. These sharing arrangements work well where there is goodwill, but the earlier examples show this system to be vulnerable where there is not. Is there, therefore, a case for more formality? Most job descriptions for newly appointed consultant psychiatrists now prescribe a definite number of sessions each week to be spent on a special interest, such as forensic psychiatry, addictions, psychotherapy, or the psychiatry of old age. We do not apparently want to appoint medical administrators for life, but we might learn from the American pattern of the appointment of a Chief of Service subject to renewal every five years. There could be a safeguard of not allowing three consecutive periods of office. It would be for the appointing service to judge whether the service had been well administered, and give it power to dismiss and replace under certain conditions. The Chief of Service would also need some form of rewards and sanctions and the support of his 
Authority in developing the service. He would not be responsible for clinical performance, which should remain the responsibility of the medical profession.

\section{The role of the Health Authority}

In a number of hospitals it is quite obvious what is wrong and often what should be done about it. The experience of Normansfield illustrates this point very well. However, although the AHA is responsible for providing a service and can be held accountable for not doing so, it appears powerless to insist on remedy, having neither rewards nor sanctions to shape the work of medical staff. There is confusion between clinical responsibility, which is the consultant's alone, and service responsibility which is shared. The ability of the Health Authority to intervene in management and service issues needs to be more clearly defined. At present the hint of confrontation is enough to cause talk of litigation and defence organizations. It should be quite routine that consultants are called to account for the way they have used the resources given to them to provide a service. Only the Regional Medical Officer or the Area Medical Officer in AHA(T)s exercise the right to suspend consultants, and even then it has to be on grounds of obvious illness or extreme moral turpitude.

\section{Conclusion}

There is evidence that there is a gap between the responsibility of a Health Authority to provide a comprehensive service and the contractual obligation of consultants to do so. Where a full service is not provided, the senior clinical staff are blamed for not meeting a responsi- bility which has not in fact been delegated to them. The Health Authority is held accountable for services over which they have no direct control.

There are some measures which might improve the position which are offered for deliberation:

(1) An alteration in the consultant psychiatrist's contract to include the principle of corporate responsibility for comprehensive mental illness service.

(2) A separation of clinical responsibility from organizational responsibility (also included in revision of contract) to restore the chain of accountability in matters of organization while leaving clinical autonomy untouched.

(3) Much improved statistics and epidemiology, so that both clinician and Authority can monitor the outcome of agreed objectives and reach a comprehensive service through more informal means.

(4) The delegation of District responsibility for medical organization (but not clinical responsibility) to an appointed and accountable individual. $\mathbf{A}$ Chief of Service with a renewable appointment and some formal powers is preferable to the medical superintendent model.

(5) More formal ways for the Health Authority to hold psychiatrists accountable for the use of resources allocated to them.

(6) Good practice should be rewarded by public acknowledgement. Enhanced public reputation is a more powerful incentive for most doctors than private financial reward.

\title{
Clinical Psychologists and Psychiatrists Working Together in the Community
}

\author{
By Michael Frost, Clinical Psychologist, All Saints Hospital and ANDree LdDel, Principal Lecturer in Psychology,
} North East London Polytechnic

Since the publication of the Trethowan Report (1977) psychologists have been encouraged to expand their role outside the more orthodox psychiatric setting. As a small and steadily developing professional group, they have attempted to gain visibility by seeking alliances with medical specialties other than psychiatry, which had provided them with a kind of sheltered environment since the inception of the National Health Service. General practitioners have probably most often been solicited in these attempts to obtain a wider recognition. The favourable response of many general practitioners created the necessary climate to stimulate clinical psychologists to carry out systematic evaluations of their contribution to primary care (McPherson and Feldman, 1977; Johnston, 1978; Ives, 1979; Koch, 1979; Earll and Kincey, 1980).

On the other hand, similar evaluation of the contribution of clinical psychologists to psychiatry had not appeared essential. Historically, clinical psychology developed as a discipline alongside psychiatry to carry out standardised psychological assessments; subsequently, its functions were extended, notably in psychological therapies, and psychologists' posts proliferated. In addition to psychiatric hospitals, clinical psychologists were sited in academic departments of psychiatry, general and district hospitals and also other settings where psychiatrists were employed. This steady growth of these employment opportunities seems to indicate that their contribution has not been in question; so, in view of the gradual devolution of psychiatric provisions outside hospitals, it seems appropriate to reconsider the contribution of clinical psychologists. This discussion focuses on the relationship between a group of clinical psychologists and psychiatrists who are providing out-patient facilities in the same health district but practising independently of each other.

\section{Setting}

Newham Health District has no psychiatric hospital within its boundaries. Goodmayes, the former West Ham 